\title{
Cloud-based Cooperation of Logistics Service Providers in Logistics Cluster Organisations
}

\author{
Jan Oberländer \\ Netzwerk Logistik Leipzig-Halle e.V., \\ Terminalring 13, 04435 Leipzig/Halle Airport, \\ Germany \\ Email: jan.oberlaender@logistik-mitteldeutschland.net
}

\author{
Bogdan Franczyk \\ University of Leipzig, \\ Information Systems Institute, \\ Grimmaische Straße 12, 04109 Leipzig, Germany \\ E-Mail: franczyk@wifa.uni-leipzig.de
}

\begin{abstract}
In today's logistics market, small and mediumsized logistics companies are exposed to increasing cooperation pressure to use rationalization potentials, win new groups of customers and assert themselves in the competition with big logistics companies yielding a distinct market power. In the past, numerous SME-size logistics companies have joined to form regional logistics associations in order to assess possible cooperation and develop cooperation potentials. In a parallel process, logistics cloud service providers develop new types of cooperation-supporting logistics cloud services. This paper describes a method of how regional logistics associations can apply a cloud-based cooperation development process. The method was developed as part of a doctoral thesis and evaluated first hand by expert interviews in several logistics association in relation to the application involved. The results of the evaluation suggest that a suitable approach was found by which regional logistics associations can tap the potentials of logistics cloud services for their member companies.
\end{abstract}

\section{INTRODUCTION}

G lobalization and the new internet-based capabilities of Teady informational networking among companies impose and enable new value-added structures known as bottom-up economy. The structure and process related nature of the bottom-up economy is dramatically different from the top-down economy of the past in that it follows a logic of cooperation among smaller, locally based value-added units flexibly combining to form larger structures to generate complex products and services [1]. This is referred to as open production by production managers and suggests that new technical opportunities might give rise to structural changes also in the logistics sector in future.

From the angle of small and medium-size logistics companies the challenge is to be able to forge ties of cooperation with other logistics service providers quickly and with as little input of resources as possible in a situation in which the cooperative business processes must be handled efficiently with the aim of providing joint logistics services in the market. The present stock of software used by small and medium-size logistics companies systematically supports isolated internal functions and is not made for easy and quick integration with the software applications of complementary partners in the value-added process. Innovative, cooperation-supporting and multitenant cooperation-enabling logistics cloud services, resp. hold out the promise of new opportunities for the short-term establishment and termination of logistics ties of cooperation without the need or risk of investment associated with conventional software applications. Meanwhile the integration issue between cooperation partners on the IT level can essentially be cleared up by the usage of the same cloud software installation.

The problem at present is less that of the availability of the suitable logistics cloud services than the introduction of new approaches for the shared use of software among SME logistics companies. Logistics associations can provide new technical approaches as source of innovation and as multiplier. The degree to which this can be realistic and the way in which such a cloud-based cooperation development process can be designed will be described below.

The argumentation structure of this paper and the underlying doctiral thesis aims on the following thesis: Logistics associations can contribute to increasing the competitiveness of small and medium-sized logistics enterprises by using the described method. This can be achieved by increasing the cooperation ability of the small and medium-sized logistics enterprises. Therefore multitenant cooperation-enabling logistics cloud services are recommended for the cooperation development that would not be used by the logistics enterprises on its own.

These thesis can be derived from the following basic consideration: A part of the small and medium-sized logistics enterprises is exposed to an cooperation pressure or rather an cooperation exigency in the logistics market to survive in the long term. A part of these logistics enterprises has a lack of ability to cooperate with other logistics companies because of insufficient in-house software products.

Some of these logistics enterprises would be able to cooperate at lower costs and in a shorter time by using multitenant cooperation-enabling logistics cloud services. However, a part of these logistics enterprises does not know about the advantaged and capabilities of logistics cloud services. They need an external suggestion to get know about cloud computing and an external support for the implementation of logistics cloud services in their own companies.

A part of the existing logistics associations in Germany and of course in other countries could provide this external support. In this case the logistics associations cloud get the 
role of logistics cloud service intermediaries between the logistics enterprises as cloud service users and the cloud service providers. However, the problem is that the logistics associations themselves need an adequate approach for the introducing of logistics cloud services together with the logistics companies. At this point, the lack of a scientifically based method is apparent which represents a such adequate approach.

The method described in this paper was developed using the paradigm of design-oriented business informatics. For this purpose, several phases have been processed: 1 . analysis phase, 2. design phase (draft of the method), 3. evaluation phase (by means of expert interviews with cluster managers of logistics associations), 4. revision phase (correction of the method design) and 5. diffusion phase (is currently taking place, for example by writing of this paper). In the following sections the results of each phase are described.

\section{State of Cooperation Capabilities of small and medium- SIZEd Logistics SERVICE PROVIDERS}

Logistics SMEs often lack the willingness or ability for cooperation and as a consequence of this they have to put up with a competitive disadvantage [2]. Schwinger and Wäscher analysed the cooperative skills of 133 SMEs in the logistics industry focusing on technical, personnel and organisational aspects of cooperation [3]. They found that 94 of the 133 logistics SMEs studied were willing to cooperate and would like to work with other companies in the industry better and more frequently whereas only 14 of the 94 companies willing to cooperate had very good cooperative skills. The two main reasons for the lack of cooperative skills are the lack of confidence in other logistics companies (social/personnel cooperative skills) and the lack of availability of IT applications capable of cooperation (technical cooperative skills) [3].

The relative importance of both obstacles to cooperation can be diminished or essentially eliminated in the long term by involving the logistics SMEs in logistics associations. Regional logistics associations can act as a suitable platforms on which social relations can grow and trust among logistics SMEs can be strengthened. Besides, these platforms can act as cloud enablers and improve the technical cooperative skills of the logistics SMEs by introducing logistics cloud services. These two aspects will be discussed in the next section.

\section{State of the Art Regarding Logistics Clusters and collaboration Types of medium-sized Logistics Service} PROVIDERS

\section{A. State of the Development of Logistics Clusters}

Numerous statistical surveys have shown that the logistics industry in Germany is dominated by small and medium-size companies; they account for approximately 97 per cent of the total number of logistics companies in this country [4], [5]. The overwhelming majority of logistics SMEs are voluntary members at least of a regional, state-wide or nationwide logistics association [6]. Reference [6] shows a quanti- tative survey of about 275 logistics associations in Germany. Logistics association, for the purpose of this study, is defined as follows:

"A logistics association is any form of non-contractual cooperation of several logistics companies by which the logistics companies involved try to attain an economic advantage. The logistics association can be institutionalized as a legal entity in which case a regional logistics association forms the cluster organization of a regional logistics cluster."

The logistics association can be considered as "precursor" of a higher developed, more complex and contract-based form of cooperation among logistics companies that emerges from the logistics association in the course of time. The logistics association can be viewed as umbrella organization under which the logistics companies develop ties of cooperation.

Starting in 2000, the development of regional logistics cluster organizations driven by regional economic actors gathered momentum[7]. On the basis of the quantitative survey by Oberländer, 64 regional logistics associations were defined in Germany that can be referred to as regional logistics cluster organizations.

\section{B. Regional Logistics Associations as “Technology rollout Networks" for Logistics Cloud Services}

The study by [6] identified the main tasks of the 64 regional logistics associations found. These include the marketing of the logistics companies of the regional logistics association (52 of 64), the exchange of information and knowhow among the member companies (44 of 64), the recruiting of personnel (36 of 64) and location marketing (33 of 64) [6].

IT-related aspects of the regional logistics associations are of significance to this publication. Totally 22 of 64 regional logistics associations are active in the fields of innovation, IT, technique, and R\&D projects; 8 of 64 provide online services, web services or Software-as-a-Service (SaaS) applications to the member logistics companies. Cloud computing is gaining in importance among the logistics associations, which was confirmed by the interviews conducted (see VI). Reference [8] names ... the identification of future trends and the utilization of new technologies particularly for SMEs as the main task of technology foresight. SMEs often lack the resources and access to the required information. It would be an advantage for many similar companies in an industry to cooperate in the field of technology elucidation so that available resources can be bundled and joint innovation projects in cloud computing and logistics cloud services initiated. Reference [9] shows that many SMEs make no use of cloud computing because the lack the competence and the capacity of taking advantage of these potentials. A suggested solution would be a cloud enabler and trust builder for SMEs in order to unlock the potentials of that technology.

These roles can be played by regional logistics associations in that they act as technology elucidators for logistics companies as far as cloud services are concerned. 


\section{Bottom-up Development of Fourth-Party-Logistics \\ Providers based on regional Logistics Associations}

Several different versions of the emergence of fourth party logistics (4PL) providers (or similar types of logistics integrators) are known [10]:

i. an original equipment manufacturer (OEM) or another large industrial / commercial company forms a subsidiary company as 4PL provider or assigns the tasks of a 4PL provider to an existing subsidiary company;

ii. a consulting firm takes over the role as $4 \mathrm{PL}$ provider for and on behalf of the value-added partners;

iii. an IT service provider takes over the role as 4PL provider for and on behalf of the value-added partners;

iv. a third party logistics (3PL) provider revises its business model and thereby becomes a 4PL provider;

v. the value-added partners (e.g., industrial or commercial company and logistics provider) form a cooperation, e.g., a joint-venture company, which takes on the role as 4PL provider;

vi. several logistics SMEs join to form a $4 \mathrm{PL}$ provider.

The versions (i. to v.) can be regarded as top-down development approaches or a mixture of top-down and bottom-up approaches. The combination of small and medium-size logistics companies fuels the interest in the bottom-up development of 4PL providers.

The emergence of regional logistics associations marks a first step in that direction. Some logistics companies are expressly formed with the aim of providing logistics SMEs with a platform on which they can cooperate. Reference [6] shows that ... about $20 \%$ of all regional logistics associations systematically deal with the mediation of logistics orders to the member companies or manage the handling of large logistics orders by several member companies. So some of the regional logistics associations already act as 4PL providers, for which logistics cloud services have hardly been used or are only in the nascent state.

IV. State of the Art regarding Cloud Services, Software and Platform for Logistics Service Providers

\section{A. Application Area of Logistics Cloud Services}

The german "Bundesverband Informationswirtschaft, Telekommunikation und neue Medien” (BITKOM) and other institutions/authors describe different scenarios for the redesign of a company's internal IT landscape due to the use of cloud services. The scenarios of using cloud services most frequently cited include the following [11]:

i. Higher flexibility of software use by the faster and simpler provision of software applications via the internet (on-demand) or outsourcing of software applications so far used internally, e.g., order management, enterprise ressource planning (ERP), supply chain management (SCM) and customer relationship management (CRM) systems; ii. Improvement of the cost variability of software use by more flexible accounting models (pay-per-use)

iii. Further development and augmentation of the internal business model by the ability of offering complementary IT services to available company services (e.g., easier IT integration of customers and value-added partners by linking them to the cloud service);

iv. Protection of critical business processes, business applications and business data by shifting them to a cloud environment with very high security requirements.

Many of the application scenarios of cloud services discussed so far aim at providing internal/company-focused advantages of cloud usage. In contrast with that, explicitly cooperation focused application scenarios are discussed much less frequently today. The benefits of the multitenant capability of SaaS applications (e.g., cost sharing, risk sharing, internet-based access, and constant availability) are in the focus of attention whereas multitenant cooperation by means of SaaS applications has received less attention. The joint use of multitenant cooperation logistics cloud services could mean that logistics SMEs willing to cooperate develop a higher degree of ability to work together than with the applications they have been using so far.

Unlike local integration of all with all applications (n:m, "mesh networking") among all network partners, the investment in IT for integration and interface development in the case of a central SaaS application with shared use is limited to the number of applications needing integration (1:n, "huband-spoke network”).

\section{B. Cloud Collaboration Platforms for Logistics Service Providers}

Major developments of cloud collaboration platforms for logistics service providers are undertaken, for example, by the EffizienzCluster Logistik Ruhr e.V. the Logistics Mall of the Fraunhofer Institute for Material Flow and Logistics (IML) [12] as well as at the Netzwerk Logistik LeipzigHalle e.V. [16] under the European project LOGICAL [13], [14], [15]. Some logistics software vendors have recognized the trend towards cooperation-supporting cloud-based logistics software and reorient their software development in that direction [17].

The technique-driven approaches to the development of cooperation platforms and cooperation-enabling logistics cloud services require an application-related and practical procedure to be able to tap the potentials of novel logistics cloud services for logistics SMEs. The best logistics cloud platforms and applications will not be used if the logistics companies are unaware of the advantages of cloud applications and their possible use for improving the cooperative skills. The regional logistics association need structured directions for activities to take all actors and aspects of cloudbased cooperation among logistics SMEs into consideration. The fundamentals of such a method will be described in the next section. 
V. Description of a method for Cloud-based Collaboration of Logistics Service Providers

\section{A. Meta Model}

The meta model of the method consists of the meta model elements result, technique, activity and actor/role, which are described in greater detail in the respective submodels.

Comprised of these four elements is the method in which structured sequences of activities by several actors or roles are performed that generate results and outputs by the application of techniques. The submodels developed by the author and evaluated in expert interviews will be described briefly in the next sections. The interview results will be discussed in detail later. The meta model is shown in Fig. 1. The description of the method in the form of models was performed with the aim to describe the method in a formal way. It is not provided to instance the models using BPML or other instantiation techniques. For the target group of logistics SMEs (as method users), it is important that the method and its components are easy to understand and easy to follow. By subsequent research and development activities there could be an instantiation of the different method models to obtain a software support of the method. This could be termed as cloud-based "computer aided cooperation development” (CACD). But this goes beyond the considerations in this paper.

\section{B. Role Model}

The role model comprises several roles on the higher level of legal entities (logistics service provider, logistics associations, logistics customers, etc.), as well as concrete roles within these legal entities (chief executive officers, commercial managers, cloud software endusers, cloud soucing project manager, logistics deciders etc.). Fig 2 shows the role model.

\section{Process Model for Logistics Collaboration \\ Development based on Logistics Cloud Services}

The approach model comprises of totally six main activities each with three or four intermediate activities which, in turn, are divided into sub-tasks. Fig. 3 shows the main activities of the process model using the business process model and notation (BPMN). For reasons of space, only the main and intermediate activities can be presented here in order to provide an overview of the process model. The process model combines, in its activities, a multitude of procedures, techniques and methods of other engineering disciplines, e.g. business engineering, systems, engineering, software engineering, service engineering, integration engineering, and requirements engineering.

The assignment of roles, results and techniques to the activities cannot be detailed here for space reasons and is described in detail in reference [6].

\section{Result/Output Model and Technique Model}

The techniques and results of all activities and their subactivities are presented in [6]. For example, the techniques include presentation and workshop techniques to describe the possible application of logistics cloud services by the project manager or cloud service provider to decision-mak-

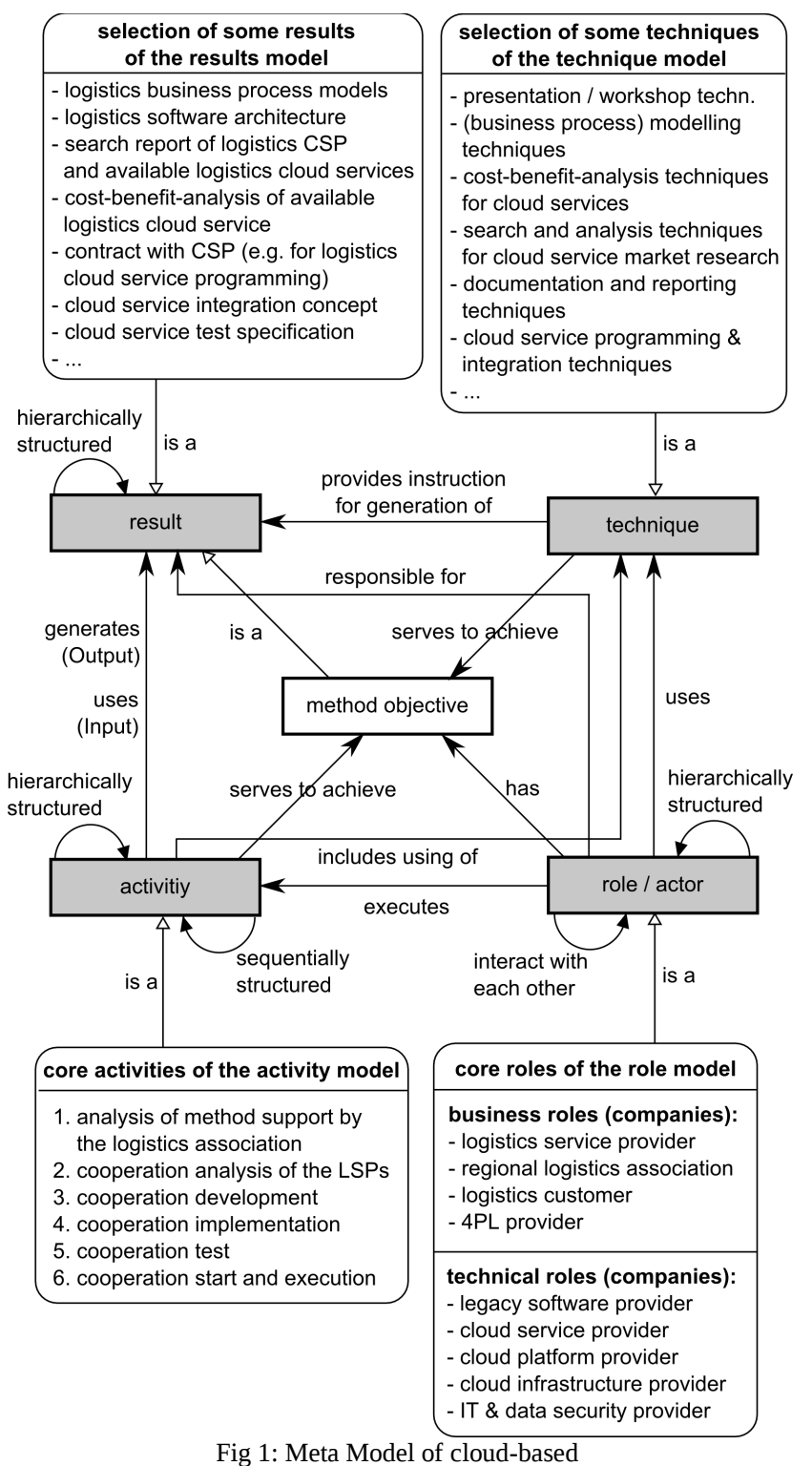

Logistics Cooperation Development

ers in the logistics association and the logistics companies.

The result and output model contains the final results of each activity that should be attained by the respective activity. These include, for example, business process models, search and market analysis results, IT system descriptions, target and performance specifications, minutes of meeting, results of cost-benefit calculations, etc.

\section{Interview Findings in German Logistics Clusters with REgARD to the MEthoD}

The four submodels were evaluated and reviewed in totally seven expert interviews with board members or cluster managers of seven German regional logistics associations in spring 2014. These interviews were opportunities for a critical assessment of the method by potential users of it. The author received a direct feedback from the logistics industry which enabled the better evaluation and improvement of the four submodels. Individual face-to-face interviews were se- 


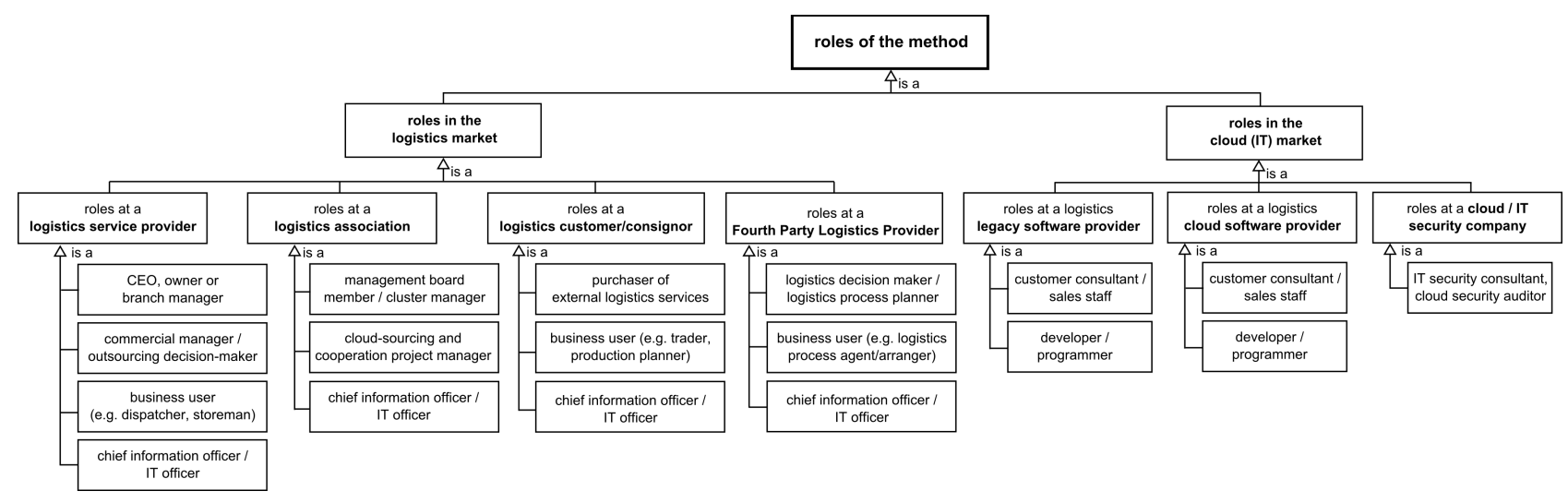

Fig 2: Role Model of cloud-based Logistics Cooperation Development

lected as evaluation method to give comprehensive explanations to the interviewee about the overall context and the objective of the approach. During the interviews, the models were extensively explained using the model charts and figures and revised using handwritten sketches. The complexity of the models is too large to get appropriate feedback exclusively by an quantitatively designed online questionnaire or another quantitative survey technique.

The results of the interviews will be discussed summarily in the following sections.

\section{A. Classification of the Interviewees}

The following persons were interviewed as representatives of their respective logistics associations. All interviewee hold managerial positions in their logistics associations. The number of member companies and the year in which the association was formed are added in brackets:

i. Prof. Dr. Uwe Arnold, Logistics Cluster Manager of the Network Logistics Leipzig-Halle e.V. (NLLH); 130 member companies, founded in 2008

ii. Mark Renner, Logistics Cluster Manager of LogistikNetz Berlin-Brandenburg e.V. (LNBB), 70 member companies, founded in 2007

iii. Michael Kluger, Logistics Manager at the House of Logistics and Mobility e.V. \& HOLM GmbH \& LogisticsCluster RheinMain, 220 member companies, founded in 2007

iv. Dr. Robert Schönberger, CEO of the Logistics Cluster Schwaben e.V. (LCS), 90 member companies, founded in 2011

v. Björn Geib, Head of Innovation at Logistik-Initiative Hamburg e.V. (LIHH), 530 member companies, founded in 2000

vi. Christian Prasse and Andreas Nettsträter, EffizienzCluster Logistik Ruhr e.V. (ECLR) / EffizienzCluster Logistik GmbH / Fraunhofer IML Dortmund, 170 member companies, founded in 2010

vii. Dr. Christian Huck, board member of the Logistics Network Thuringia e.V. (LNT), 40 member companies, founded in 2008

The interviews were conducted on the basis of a uniform questionnaire with entirely open questions and lasted for 90 to 160 minutes. The interview contained questions on the following subjects:

i. Problems with regard to the cooperative skills of the logistics SMEs member of the logistics association (see II.)

ii. Characterisation of the logistics association and its organisational structure (see III.)

iii. Activities and projects of the logistics association in cloud computing (see IV.)

iv. Feedback as to the quality of the method (see V.)

The results of the interviews will be described briefly below. Reference [6] contains the complete interview results.

B. Interview Findings regarding the Cooperation Aspects

All interviewees confirmed that the logistics SMEs are exposed to extrinsic cooperative pressure and the need for cooperation was high in view of the requirements of the logistics market.

Some logistics companies therefore decide to join a logistics association; small and medium-sized logistics companies tend to join a regional logistics association whereas large logistics companies and groups prefer membership in national or state-wide logistics associations. The spatial and social closeness among the logistics SMEs within a regional logistics association tends to improve their spirit or readiness for cooperation, with one of the major obstacles to cooperation, i.e., lack of confidence in potential cooperation partners, being alleviated in part.

All interviewees also confirmed that the cooperative skills of the logistics SMEs were not unlimited but still running significant deficits as a result of, for example, poor IT equipment (such as incompatible software applications or poor interfaces).

Thus, those interviewed confirmed the hypothesis of limited cooperative skills due to the lack of IT capabilities among small and medium-size logistics companies.

\section{Interview Findings regarding Cloud Computing and} the Concept of Bottom-up-based 4PL Providing

For the time being, cloud computing receives intensive attention only by some logistics associations. Only 2 of 7 interviewees said that projects in cloud computing had been 


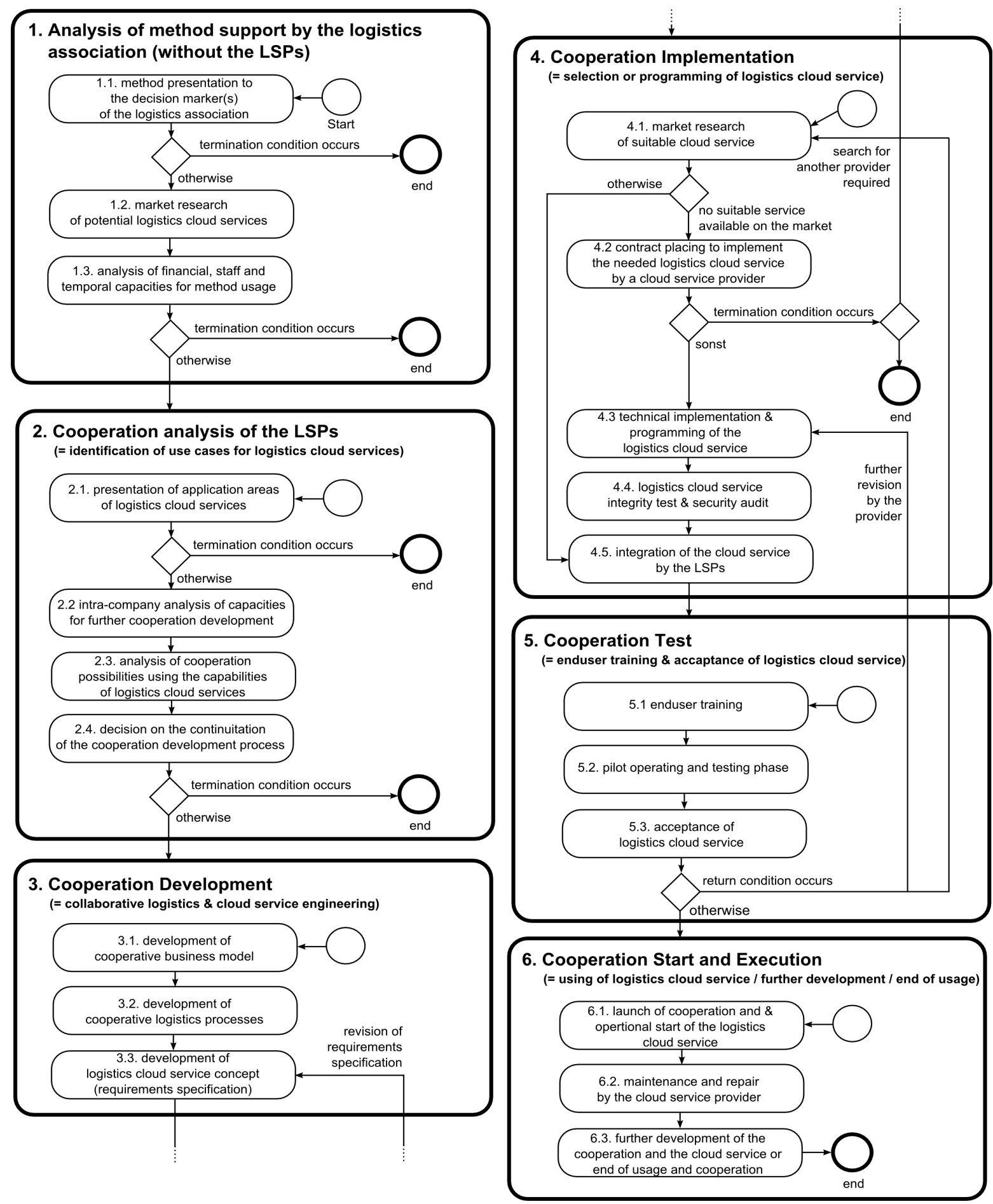

Fig 3: Process Model of cloud-based Logistics Cooperation Development

initiated and the developments in this innovative field were followed and promoted actively. Another 2 interviewees at least accompanied workshops, lectures and other events on cloud computing, for example, to present the solutions of logistics cloud service providers and discuss them with the logistics companies. The 3 other interviewees had not so far dealt with cloud computing but were planning to do so in future.
The concept of 4PL providers was known to 4 of 7 interviewees and as such does not represent is common knowledge of potential forms of cooperation of logistics companies in the logistics industry.

Only 2 of 7 interviewees ever thought of developing a 4PL provider with regional activities within or parallel with the available regional logistics association, however none of 7 logistics associations interviewed actually set it up. After the theoretical concept had been explained, 5 of 7 intervie- 
wees said it was difficult to imagine at present but not unrealistic in the long term.

\section{Interview Findings regarding the Method}

To explain a potential solution to the current lack of technical cooperative skill among logistics SMEs, the possible application scenarios for logistics cloud services were explained and the method described with reference to the role model, procedure model, technique model and result model in the next step. These explanations took about 30 minutes. After that, those interviewed were asked whether the four submodels were complete, understandable and of practical relevance (applicable). The interviewees provided a very comprehensive and critical feedback and added further aspects to all four models, e.g.:

i. New roles (e.g., IT security advisor / auditor to verify the technical security of the logistics cloud service),

ii. New activities (acquisition of subsidies to support innovation for the introduction of cloud services),

iii. New techniques (e.g., a forecast calculation to assess the long-term benefits associated with the use of the logistics cloud services), and

iv. New result types (logistics cloud platform model, where several logistics cloud services are available to the members of a logistics association on a central platform.)

Reference to the additional roles and activities was already made in section $\mathrm{V}$. The principal question of the discussion of the submodels was that of the possible application of the method in the regional logistics association each of the interviewees represented.

Totally 5 of 7 interviewees confirmed that the method could be applied to provide the associated logistics SMEs with a new technological roadmap for developing cooperation. 2 of 7 interviewees said the method was correct and made sense but their logistics association was not pursuing activities towards developing cooperation among members. However, these two interviewees were agreed that they might apply the method if the support of the development of cooperation was the task of the logistics association.

\section{Conclusions}

The quantitative analysis of regional logistics associations in Germany has shown that the support of cooperation and IT/innovation are direct activities in which numerous associations engage but cloud computing and logistics cloud services are not sufficiently known yet.

The qualitative analysis of selected regional logistics association was able to show that the majority of the logistics SMEs is exposed to pressure for cooperation but only some logistics companies have the required cooperative skills due to the general lack of access to light-weight and low-priced software applications facilitating cooperation.

The investigation of logistics associations as cloud-enabler has not been carried out in Germany before and is described in this paper for the first time. To develop the method, the cloud migration approaches of other authors were used and applied to the special circumstances of logistics SMEs and the innovation potentials of logistics associations. Quantitative indicators for the usefullness of logistics cloud services especially for logistics SMEs were given by the detailed, quantitative company surveys of the Fraunhofer IML in Dortmund [20].

The overwhelmingly positive assessment of the method by those interviewed is encouraging and underlines the need for an application-oriented and comprehensive guideline of action for regional logistics association to provide cooperation support for their members by applying multitenant cooperation-enabling logistics cloud services.

\section{ImPlications for fURTher Research ANd DeVelopment}

The development of cloud services for the logistics industry is making rapid progress. At the same time as cloud service providers develop cloud services, cloud platforms comprising the cloud services of several individual providers emerge. The same development can also be seen in the logistics sector, where the number of logistics cloud platforms is increasing. Several logistics association have developed their own logistics cloud platform strategy and try to offer their members in the logistics sector new technical opportunities of developing cooperative logistics business models. Areas in which further research is needed and new questions must be answered include the following:

i. The further development of multitenant logistics cloud services to multitenant cooperation logistics cloud services by the respective providers;

ii. The development of business models and legal frameworks of logistics cloud platform providers [18];

iii. Ensuring the integrability of different logistics cloud services of the same or different cloud service platforms on technical and semantic levels;

iv. Ensuring data protection, data security, confidentiality and integrity in cloud environments and of cloud service based business processes [19];

v. The development of transnational logistics cloud platforms because logistics processes have no regard for national borders;

vi. The integration of public (e.g., customs authorities) and quasi-public actors (e.g., seaports, airports, freight distribution centres, etc.) in the logistics industry in the logistics cloud environments (cloudbased logistics e-government)

The use of logistics cloud services in future could enable logistics SMEs to combine and form 4PL providers in the same way as bottom-up logistics cloud platforms are composed of the logistics cloud services of individual providers.

\section{REFERENCES}

[1] T. Redlich: "Value creation in bottom-up economics" (Wertschöpfung in der Bottom-up-Ökonomie), Springer-Verlag, Berlin, 2011, pp. 1-5, DOI: 10.1007/978-3-642-19880-9.

[2] U. Arnold, J. Oberländer, S. Mutke: "Milestone Report 1.1 about Requirements and Test Szenarios for Logistics Services", BMBFProject InterLogGrid, Logistics Community of D-Grid Initiative, 2010. 
[3] D. Schwinger, G. Wäscher: "Maturity for virtual companies” (Reif für das virtuelle Unternehmen?), in: Schmalenbachs Zeitschrift für betriebswirtschaftliche Forschung, 58. Year, vol. 3, Verlagsgruppe Handelsblatt, 2006, pp. 390-424, DNB: http://d-nb.info/96784391X.

[4] BGL: Bundesverband Güterkraftverkehr, Logistik und Entsorgung e.V.: "Statistics about road haulage in Germany" (Statistiken zum gewerblichen Güterkraftverkehr in Deutschland), 2014. [Online] Available: http://www.bgl-ev.de/web/daten/index.htm.

[5] BAG: Bundesamt für Güterverkehr: "Structure of companies for german road haulage” (Struktur der Unternehmen des gewerblichen Güterkraftverkehr in Deutschland), Köln, 2012. [Online] Available: http://www.bag.bund.de/SharedDocs/Downloads/DE/Statistik/Unterne hmen/Ustat/Ustat_2010.html.

[6] J. Oberländer: "Method for Development of web-based Cooperations of small and medium-sized Logistics Service Providers” (unpublished doctoral thesis, submission midyear 2014).

[7] W. Elsner, J. A. Hübscher, M. Zachzial: "Regional Logistics Clusters Statistical survey, strengths and weaknesses, action potentials (Regionale Logistik-Cluster: Statische Erfassung, Stärken und Schwächen, Handlungspotenziale), Peter Lang Europäischer Verlag der Wissenschaften, Frankfurt/Main, 2005, pp. 3-21, DNB: http://dnb.info/976630370.

[8] C. Mieke: "Technology introduction in company networks" (Technologiefrühaufklärung in Netzwerken), Deutscher UniversitätsVerlag, Wiesbaden, 2006, DOI: 10.1007/3-8350-5715-4.

[9] T. Haselmann: "Cloud services for small and medium-sized companies - benefits, approach and costs” (Cloud-Services in KMU - Nutzen, Vorgehen und Kosten), Verlagshaus Monsenstein und Vannerdat, Münster, 2012, pp. 263, DNB: http://d-nb.info/ 1024981452.

[10] F. Kasiske: "Road to the Management of the Supply Chain" (Wege zum Management der Supply Chain) in: H. Baumgarten, I.-L. Darkow, H. Zadek: "Supply Chain Management and Services - Management of Global Supply Chains by Logistics Service Providers”, SpringerVerlag, Berlin, 2004, pp. 151-156, DNB: http://d-nb.info/970085117.

[11] BITKOM: Cloud Computing: Evolution of Technology, Revolution of Business, 2009. [Online] Available: http://www.bitkom.org/files/ documents/BITKOM-Leitfaden-CloudComputing_Web.pdf
[12] D. Daniluk, J. Rahn, M.-B. Wolf: "Logistics Mall - cloud-based logistics software” (Logistics Mall - Logistiksoftware aus der Cloud) in: Journal of Business Informatics and Management, vol. 1, SpringerVerlag, Berlin, 2014, pp. 28-37, DNB: http://d-nb.info/ 992716098.

[13] U. Arnold: "Cloud logistics - the user perspective" (Cloud Logistics die Anwenderperspektive) in Journal of Business Informatics and Management, vol. 1, Springer-Verlag, Berlin, 2014, pp. 16-27, DNB: http://d-nb.info/992716098 .

[14] U. Arnold, J. Oberländer, B. Schwarzbach: "LOGICAL - Development of Cloud Computing Platforms and Tools for Logistics Hubs and Communities". In: Proceedings of the Federated Conference on Computer Science and Information Systems, Wrocław, pp. 1083-1090 (2012), ISBN: 978-1-4673-0708-6.

[15] U. Arnold, J. Oberländer, B. Schwarzbach: “Advancements for Cloud Computing in Logistics”. In: Proceedings of the Federated Conference on Computer Science and Information Systems, Wrocław, pp. 10551062 (2013), ISBN: 978-1-4673-4471-5

[16] U. Arnold, J. Oberländer: “Annual Report 2013 of Logistics Network Leipzig-Halle e.V.” (Jahresbericht 2013 des Netzwerk Logistik Leipzig-Halle e.V.), 2014 [Online] Available: http://www.logistikleipzig-halle.net/uploads/tx_abdownloads/files/Jahresbericht NLLH_2013_web.pdf, pp. 20-23, (2014).

[17] G. Teichmann: "Cloud-based collaboration in logistics" (Cloudbasierte Kollaborationen in der Logistik) in Journal of Business Informatics and Management, vol. 1, Springer-Verlag, Berlin, 2014, pp. 56-65, DNB: http://d-nb.info/992716098.

[18] A Kawa, M. Ratajczak-Mrozek: "Cooperation between Logistics Service Providers Based on Cloud Computing”. In: Intelligent Information and Database Systems , Kuala Lumpur, pp. 458-467 (2013), DOI: 10.1007/978-3-642-36543-0_47.

[19] BMBF project : "Cloud Computing: efficient cooperation without security risks”, 2014 [Online] Available: http://www.vdivdeit.de/KIS/sichere-ikt/sicheres-cloud-computing/prestige.

[20] M. ten Hompel (Ed.): “Cloud Computing for Logistics 2" (Cloud Computing für Logistik 2), Fraunhofer Verlag, Stuttgart, 2013, DNB: http://d-nb.info/1041945531. 